\title{
Mobile Banking and Sustainable Growth
}

\author{
Atul Srivastava \\ Department of Management Studies, Lal Bahadur Shastri Institute of Management and Technology, \\ 29 Theatre Road, Cantonment, Bareilly, Uttar Pradesh, Pin-243001, India
}

Received 2012-04-16; Revised 2014-01-30; Accepted 2014-02-10

\begin{abstract}
The paper discusses about awareness of mobile banking services and their possible contribution towards sustainable growth. This study attempts to look into the issues regarding mobile banking services and their possible contribution in financial inclusion in India. With the help of this study author tries to focus those areas where banks can provide these mobile banking services. If this service is adopted in a positive manner it can drastically change the scenario of Financial Inclusion. For a successful financial inclusion i.e., inclusive growth, in this era, combination of both the services i.e., banking as well as mobile is very much required. Mobile banking which can be termed as virtual banking can do wonders for the economy, because these days growth in economy is possible with the help of financial inclusion and in current scenario, statistics reveals that it is very easy with the help of mobile banking. This study has been done in two phases. First phase discusses about awareness of M-banking services and Second phase discusses about possible contribution of mobile banking towards financial inclusion. M-banking in India, as assessed by the govt. can work as a potent tool for financial inclusion, is yet to clear many hurdles before it can fulfill its objective of reaching the unbanked population. In fact including rural subscribers in the banking net can help in inclusive growth, as it not very difficult to go for a mobile phone rather than going for a computer in rural areas. This service can do wonders if implemented effectively and sincerely. If any service is provided, there are always two sides, supply side and demand side. M-banking in India, as assessed by the govt. can work as a potent tool for financial inclusion, is yet to clear many hurdles before it can fulfill its objective of reaching the unbanked population. If this service is adopted in a positive manner it can drastically change the scenario of Financial Inclusion.
\end{abstract}

Keywords: Financial Inclusion, Impact, Mobile Banking

\section{INTRODUCTION}

Mobile banking has revolutionized the banking operations. Before the services of mobile banking were introduced it was perceived that if this facility is given to the customers then it will become problematic for banks to manage these services but thanks to I.T. services that this service has become very much popular. M-banking is a secure banking operation by which services of banks like banking, credit card loan, bill payment and pre-paid mobile recharge can be accessed from customers mobile phone anytime and anywhere. It is a revolutionary concept in the field of banking. In fact every field has seen some revolutions and because of those revolutions, that particular field as well as general public has been benefited. The same can happen with mobile banking, if taken in right context by general public. This service is available on $24 * 7$ basis and the process of getting the transaction completed is $20-30 \mathrm{sec}$. Although there are some security issues in the minds of the customers but this is because of their lack of awareness about this facility. All the messages originating from mobile banking applications are encrypted end to end using 128bit AES encryption, i.e., Passwords are protected up to 128 words. So its security too cannot be challenged. In fact by seeing the advantages of mobile banking RBI too has increased the daily transaction limit of mobile banking from Rs. 5000 to 50000 . This facility can be availed just at the press of a mobile's button. It offers a very wide variety of features to make banking 
convenient: Balance enquiry, Fund transfer, Bill payment, Last 5-transactions, Mobile top-up, Top-up of Tata sky, Big TV, Dish TV Request for cheque book, Book Air/Train tickets. Mobile banking can also help banks and microfinance institutions in better credit management. It can work as a tool regarding the burning issue i.e., financial inclusion. It is being considered as the most cost effective way of doing transactions. Users of banking services i.e., customers were very much scared about internet banking initially but now all the apprehensions of customers have been warded off by the bankers. The same is going to happen with mobile banking. Just because of its popularity and volume of transactions done via mobile banking, government has removed the cap of transaction limit of Rs.50,000 per customer per day, but government has transferred the responsibility of risk management towards banks. Banks may place per transaction limits based on their own risk perception. According to the trend shown by mobile banking operations a research was conducted in Bareilly district.

\subsection{Objective of the Study}

The paper attempts to explore the following:

- To assess the awareness level of consumers regarding features of mobile banking

- To assess the impact of policy initiatives of RBI on consumers especially in Bareilly district

- To measure the potential of rural market towards mobile phones, which can help in financial inclusion

- To assess the feasibility of mobile banking in rural areas

\subsection{Literature Review}

There are nearly 600 million mobile subscribers in the country but only half of that have got bank accounts. It is very easy to tap them.

In fact including rural subscribers in the banking net can help in inclusive growth, as it not very difficult to go for a mobile phone rather than going for a computer in rural areas.

Because of this it has become an effective channel for conducting mass banking.

PWHC (2011), shows that the total revenue expected from mobile banking is Rs 2600 crore by 2015. The report further states that $\mathrm{M}$ banking can help banks as well as MFIs to deliver and collect credit in a faster and cheaper way. The study concludes on the note that the
Mobile banking is the cost effective way of doing banking transactions but his study is silent about perception of consumers as well as awareness towards mobile banking services.

According to a study done by TRAI (2010), 41\% of the urban population and $60 \%$ of the rural population in India do not have access to bank accounts. In such a scenario mobile banking has emerged as an opportunity to bring vast population in the fold and increase financial inclusion. Mobile banking is prevalent throughout the globe and here some models are being given which are already being adopted by different countries (TNI, 2011; CMFR, 2011; Mahmood and Ahmad, 2010).

Mobile banking can be regarded as financial innovation, as it reduces the cost of reaching out the poor. Financial Innovation can be regarded as a process which reduces costs, reduces risks, provides an improved product and the same is being done by mobile banking. A research done by Ramaswamy et al. (2000) and Panda (2009) points out that with the improvement of ICT infrastructure, transaction costs decrease and output increases for firms influencing various sectors of economy. This research recommends increased investment in infrastructure. In this scenario combination of banking services with ICT was a required thing which banks took into account and because of combination of these two services mobile banking took birth. M-banking in India, as assessed by the govt. can work as a potent tool for financial inclusion, is yet to clear many hurdles before it can fulfill its objective of reaching the unbanked population.

M-PESA in Kenya included $50 \%$ of all the adults in nation towards mobile banking in less than 4 years. How much fruitful it can be for our country, it is evident from the example of Kenya (Table 1).

\subsection{Future of Mobile Banking in India}

This service can do wonders if implemented effectively and sincerely. If any service is provided, there are always two sides, supply side and demand side. M-banking in India, as assessed by the govt. can work as a potent tool for financial inclusion, is yet to clear many hurdles before it can fulfill its objective of reaching the unbanked population. M-banking in India, as assessed by the govt. can work as a potent tool for financial inclusion, is yet to clear many hurdles before it can fulfill its objective of reaching the unbanked population. M-PESA in Kenya included $50 \%$ of all the adults in nation towards mobile banking in less than 4 years. How much fruitful it can be for our country, it is evident from the example of Kenya. 
Table 1. Different models for M-banking adopted by different banks in different countries

\begin{tabular}{|c|c|c|}
\hline Model & Characteristics & Functionalities \\
\hline Alternative banking model & $\begin{array}{l}\text { (1) Banks use mobile phone as a mediator } \\
\text { between bank and its customer. } \\
\text { (2) Customer needs to register his mobile } \\
\text { number with the bank. }\end{array}$ & Balance enquiry, alerts, funds transfer. \\
\hline Virtual banking model & $\begin{array}{l}\text { (1) Banks have no role to play. } \\
\text { (2) The entire service is provided by Mobile } \\
\text { Service providers by acting as a virtual bank. } \\
\text { (3) Mobile service providers charge for these } \\
\text { services on pre paid cards or post paid bills. } \\
\text { (4) Mobile service providers use mobile balance } \\
\text { too as virtual currency. } \\
\text { (5)This model can help in financial inclusion too if } \\
\text { this model is accepted by our central bank by doing } \\
\text { proper amendment in Banking regulation act. }\end{array}$ & For all the banking services \\
\hline Bank on mobile model & $\begin{array}{l}\text { (1) In this model it is proposed that mobile service } \\
\text { providers should have a tie up with banks. } \\
\text { (2) Currently in India two big tie-ups between } \\
\text { Vodafone-ICICI Bank and Bharti Airtel-SBI are } \\
\text { suitable examples of this model. }\end{array}$ & For all the banking services \\
\hline
\end{tabular}

\subsection{Research Methodology}

Research methodology used in this study was descriptive. This study has been done with the help of structured questionnaire. Responses were taken from them and then those responses were analyzed. This study was done in December month of 2011. This study has been done in two phases. In first phase of study a sample of 150 people was chosen in Bareilly zone. In this research the sample was a heterogeneous sample in which some urban and some rural people were asked some questions. This research was done with the help of a questionnaire. The research was done to check the awareness level of banking services consumers towards mobile banking. To analyze the findings chi- square analysis was used. First Phase of this study tries to measure the awareness of mobile banking services and second phase of the study tries to evaluate possible contribution of mobile banking services towards inclusive growth.

After analyzing primary data obtained here, various secondary data have been used to see the potential of mobile services in rural areas. This research has been done in two phases. In first phase i.e., with the help of Table 1 and 2, the awareness level of customers regarding mobile banking services has been analyzed and in second phase its possible contribution towards microfinance has been analyzed.
Table 2. Awareness Level about mobile banking services

\begin{tabular}{lcc}
\hline Awareness & No. of respondents & Percentage \\
\hline High (Above 60) & 93 & 62 \\
Low (Below 60) & 57 & 38 \\
Total & 150 & 100 \\
\hline
\end{tabular}

\subsection{First Phase of the Study}

\subsubsection{Findings and Data Analysis}

Findings relating to awareness about Mobile banking services in Bareilly district are shown in this Table 2.

Above table shows that out of total sample $62 \%$ were aware about mobile banking services whereas $38 \%$ respondents were not totally aware about mobile banking services. The sample was a heterogeneous sample in which some urban and some rural people were asked some questions. This research was done with the help of a questionnaire. A sample of 150 people was chosen this research. The research was done to check the awareness level of banking services consumers towards mobile banking. Out of this research it was concluded that there is a good level of awareness towards mobile banking services.

With the help of the same questionnaire association between socio economic characteristics and awareness towards mobile banking services was measured. The association between independent variables, namely age, marital status, gender, qualification, education, occupation was examined, which is being shown below Table 3 . 
Table 3. Impact of Socio economic characteristics on awareness towards Mobile banking

\begin{tabular}{lccll}
\hline Socio economic Characteristics & Table value & $\begin{array}{l}\text { Calculated value } \\
\text { (chi square) }\end{array}$ & $\begin{array}{l}\text { Degree of } \\
\text { freedom }\end{array}$ & \begin{tabular}{l} 
Result \\
\hline Age
\end{tabular} $5^{\text {Gensignificant }}$ \\
Gender & 3.841 & 1.276 & 2 & 1 \\
Educational qualification & 5.991 & 1.089 & 2 & Insignificant \\
Family Income & 5.991 & 6.985 & 2 & Significant \\
Marital status & 3.841 & 3.441 & 1 & Insignificant \\
No. of earning members in the family & 3.841 & 0.003 & 1 & Insignificant \\
Occupation & 11.070 & 1.008 & 4 & Insignificant \\
\hline
\end{tabular}

Source: Primary data

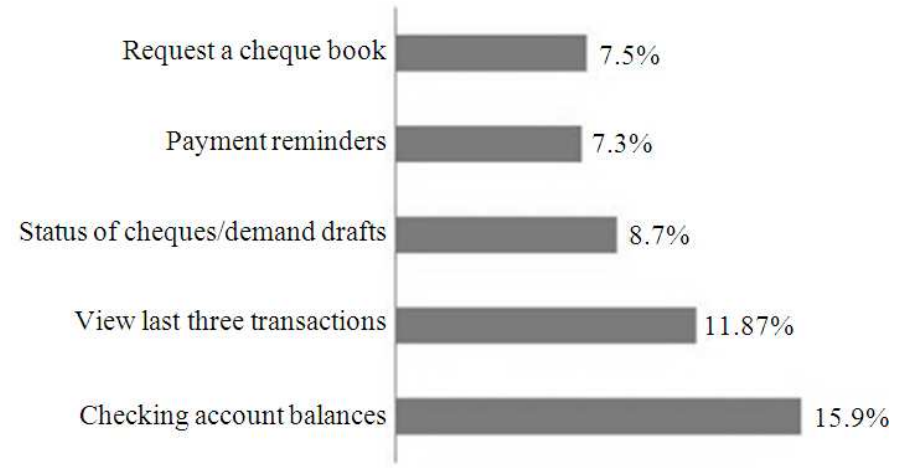

Fig. 1. Second phase of the study various reasons for resorting to Mobile

From the above analysis it is clearly evident that there is a significant association between educational qualification and awareness of mobile banking services. In rural areas most of the people are illiterate; we need to make them aware about these services and security issues about these services.

\subsection{Second Phase of the Study}

\subsubsection{Various Reasons for Resorting to Mobile Banking Services}

It has been observed that people resort to mobile banking services for these reasons (Fig. 1).

The above graphical representation depicts various reasons for using the mobile banking services. It is very much evident here that awareness regarding mobile banking services is lacking in these areas (Table $\mathbf{4}$ and 5).

In the second phase of the study it has been tried to see the possible contribution of mobile banking towards financial inclusion with the help of data available regarding reach of tele services (Fig. 2).

It is evident from the above chart that rural areas are having enough potential regarding wireless telephone market. If telecom service providers move towards rural market they will get enough business and this can work as a boon regarding financial inclusion too.

Telecom service providers (In India) have divided the districts into different circles and it will be observed that penetration of M-banking services in which area can be most fruitful (Table 6).

Total 22 Telecom circles are present in India at present. Telecom Circles are divided into 4 groups: 'metro circles' and then 'A', 'B' and ' $C$ ' circles. The 'metro' circles cover very dense population centers in the very largest Indian cities: Delhi, Kolkata and Mumbai. The 'A', 'B' and ' $\mathrm{C}$ ' circles cover various geographic territories of varying population sizes. ' $\mathrm{A}$ ' circles are the largest in terms of population coverage. ' $\mathrm{C}$ ' circles contain the smallest population. The circles listed above are the officially recognized circles as stated by the India Department of Telecommunications. India telephone companies may or may not conform to this exact usage (Fig. 3).

It is clearly evident from the above graph that monthly growth rate in Circle-C cities is higher, so the focus of mobile services providers is this only. Now the need is to make them aware about these mobile banking services which can work like 'a dream come true' for govt. As the scheme M-PESA has done wonders in Kenya. 
(\%)

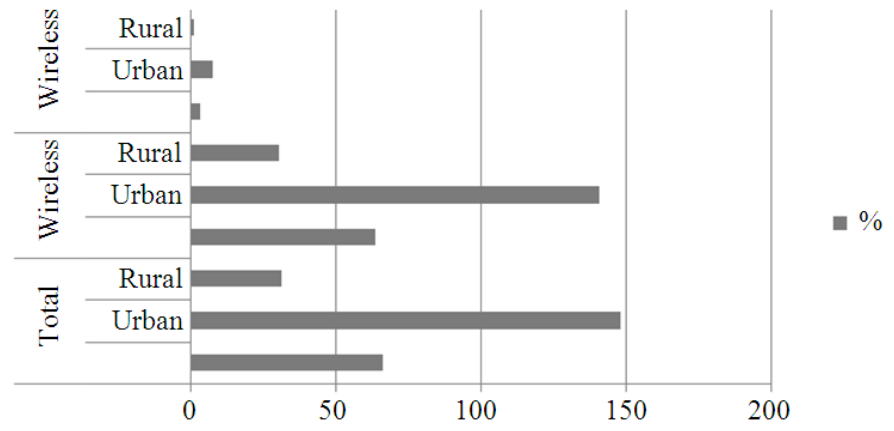

Fig. 2. Tele density in India-a graphical representation

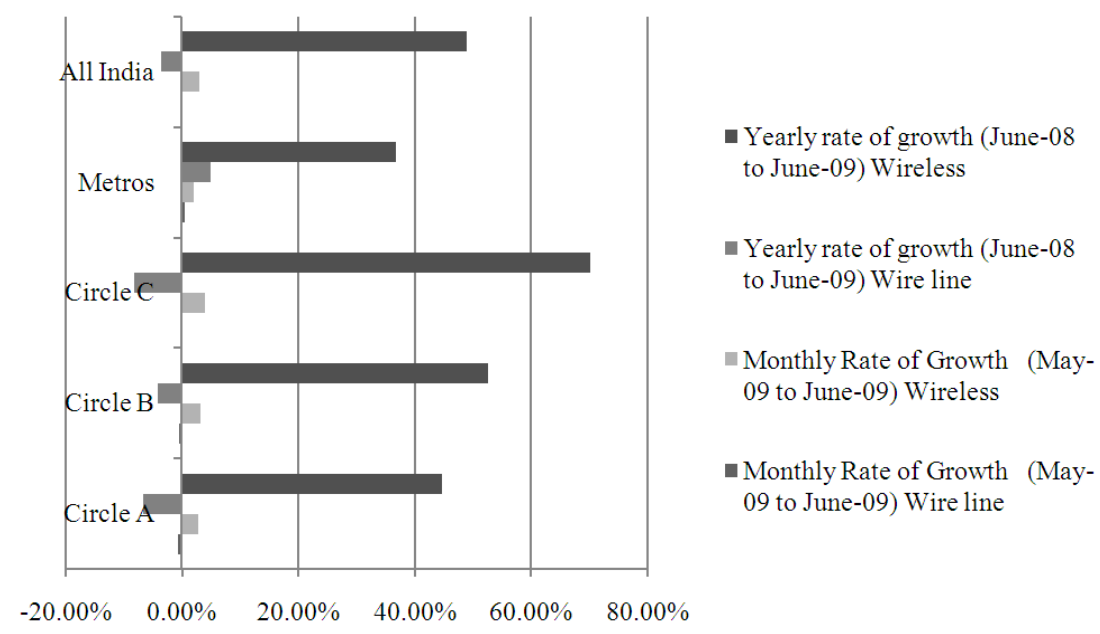

Fig. 3. Graphical representation of data in Table (7) Source: www.telecomindiaonline.com/accessed on10th April 2012

Table 4. Survey results (survey conducted in Bareilly district of India)

\begin{tabular}{llr}
\hline & Yes (\%) & No (\%) \\
\hline Respondents, having concern about the time taken by banks regarding transactions & 95.2 & 4.8 \\
Proportion having any concern regarding mobile banking service & 82.0 & 18.0 \\
Awareness campaigns launched by banks time to time & 70.3 & 29.7 \\
Proportion of respondents who are from rural areas & 41.3 & 58.7
\end{tabular}

Source: Primary data

Table 5. Tele density in India (A categorization between rural and urban outreach)

\begin{tabular}{llr}
\hline Tele-density & & $\%$ \\
\hline Total & & 66.16 \\
& Urban & 147.88 \\
& Rural & 31.18 \\
Wireless & & 63.22 \\
& Urban & 140.53 \\
Wire line & Rural & 30.11 \\
& & 2.95 \\
& Urban & 7.35 \\
\hline
\end{tabular}

Source: www.telecomindiaonline.com/accessed on 10th April 2012 
Table 6. Telecom circles in India

\begin{tabular}{lll}
\hline SN & Telecom circle name & Circle type \\
\hline 1 & Delhi Metro Telecom Circle & Metro \\
2 & Mumbai Metro Telecom Circle & Metro \\
3 & Kolkata Metro Telecom Circle & Metro \\
4 & Gujarat Telecom Circle & A \\
5 & Karnataka Telecom Circle & A \\
6 & Tamil Nadu Telecom Circle & A \\
7 & Andhra Pradesh Telecom Circle & A \\
8 & Maharashtra Telecom Circle & A \\
9 & Haryana Telecom Circle & B \\
10 & Punjab Telecom Circle & B \\
11 & Kerala Telecom Circle & B \\
12 & Rajasthan Telecom Circle & B \\
13 & West Bengal Telecom Circle & B \\
14 & Uttar Pradesh (West) Telecom Circle & B \\
15 & Madhya Pradesh Telecom Circle & B \\
16 & Uttar Pradesh (East) Telecom Circle & B \\
17 & Bihar Telecom Circle & C \\
18 & Northeast Telecom Circle & C \\
20 & Assam Telecom Circle & C \\
21 & Orissa Telecom Circle & C \\
\hline
\end{tabular}

Source: www.telecomindiaonline.com/accessed on10th April 2012

Table 7. Category-wise growth rate in access service category-wise growth rate in access service

\begin{tabular}{lcccc}
\hline & $\begin{array}{l}\text { Monthly rate of growth } \\
\text { (May-09 to June-09) } \\
\text { Care line (\%) }\end{array}$ & $\begin{array}{l}\text { Monthly rate of growth } \\
\text { (May-09 to June-09) } \\
\text { wireless (\%) }\end{array}$ & $\begin{array}{l}\text { Yearly rate of growth } \\
\text { (June-08 to June-09) } \\
\text { wire line (\%) }\end{array}$ & $\begin{array}{l}\text { Yearly rate of growth } \\
\text { (June-08 to June-09) } \\
\text { wireless (\%) }\end{array}$ \\
\hline Circle A & -0.64 & 2.7 & -6.6 & 44.6 \\
Circle B & -0.49 & 3.1 & -4.2 & 52.6 \\
Circle C & -0.32 & 3.9 & -8.3 & 70.2 \\
Metros & 0.43 & 2.0 & 5.0 & 36.8 \\
All India & -0.32 & 2.9 & -3.5 & 48.9 \\
\hline
\end{tabular}

\section{CONCLUSION}

- The model which Kenya has adopted i.e., M-PESA, should be adopted in our country too and if not practically feasible in present circumstances then too, a model like it should be instituted which can help in inclusive growth too

- It is possible provided, our $\mathrm{BC} / \mathrm{BF}$ are made aware of it and they transcend this knowledge to rural people too

- Most of the people are not aware about the mobile banking services. So people should be made aware about its key features, necessarily security features

- Rural areas are having enough potential regarding wireless telephone market. If telecom service providers move towards rural market they will get enough business and this can work as a boon regarding financial inclusion too

- In rural areas most of the people are illiterate; it is required to make them aware about these services and security issues about these services

\section{REFERENCES}

TRAI, 2010. Telecom regulatory authority of India. TNI, 2011. Telecom News India.

PWHC, 2011. A report submitted by price water house coopers.

CMFR, 2011. Bankers Institute of Rural development. Centre of Micro Finance Research.

Panda, D.K., 2009. Understanding Microfinance. 1st Edn., Wiley, India, pp: 203.

Mahmood, T. and M.I. Ahmad, 2010. Technical efficiency of microfinance institutions in India- a stochastic frontier approach. Munich Personal RePEc Archive.

Ramaswamy, S., R. Rastogi and K. Shim, 2000. Efficient algorithms for mining outliers from large data sets. Proceedings of the ACM SIGMOD International Conference on Management of Data, May 15-18, ACM Press, New York, USA., pp: 427-438. DOI: $10.1145 / 335191.335437$ 